OPEN ACCESS

Edited by:

Ubiratã Tortato,

Pontifical Catholic University of

Parana, Brazil

Reviewed by:

Roberto Gregorio Da Silva Junior,

Federal University of Paraná, Brazil

Leandro Angelo Pereira,

Federal Institute of Education, Science and Technology of Paraná, Brazil

Marco Tregua,

University of Naples Federico II, Italy

*Correspondence:

Katrin Zulau

zulauf@wirtschaft.uni-kassel.de

Specialty section:

This article was submitted to

Sustainable Organizations,

a section of the journal

Frontiers in Sustainability

Received: 22 February 2021 Accepted: 27 May 2021

Published: 02 July 2021

Citation:

Zulauf K and Wagner R (2021) Urban and Rural Sustainability: Divergent

Concepts and Their Consequences

for Marketing.

Front. Sustain. 2:670866

doi: 10.3389/frsus.2021.670866

\section{Urban and Rural Sustainability: Divergent Concepts and Their Consequences for Marketing}

\author{
Katrin Zulauf* and Ralf Wagner \\ Sustainable Marketing, University of Kassel, Kassel, Germany
}

Most sustainability innovations are adapted to the needs of urban areas. These innovations are either not offered at all in rural areas (e.g., car sharing) or require massive effort and restrictions to be usable or effective (e.g., ride sharing). Delving deeper than the description scholarly research needs to clarify consumers' conceptualization of sustainability in urban and rural areas. Notably, the extent to which sustainable innovations are adopted and their associated adoption dynamics with the consequences for marketers, consumers and society differ between urban and rural. Two research questions are pressing: (i) How do conceptualizations of sustainability differ between rural and urban living consumers? (ii) Which consequences for sustainable marketing management arise from differences and similarities of upstream innovations with downstream dynamics in urban and rural areas? Despite the wide range of previous research, the question of whether consumers living in urban and rural areas have a similar understanding of "sustainability" has not been comprehensively addressed. We consider the literature on both the intention-action gap in sustainability and Value-Belief-Norm Theory. This provides researchers with guidance to reveal divergences in values, motives and enablers for sustainability among people in urban and rural areas. Studies that deepen the understanding of how innovative service and product offers need to be designed to the specificities of urban and rural environments, contribute to clarifying consumers' intention-action gap.

Keywords: sustainable marketing, urban, rural, sustainable consumers, intention-action gap

\section{INTRODUCTION}

Previous work has aptly outlined the steps marketers can take to identify, foster and evaluate sustainable consumer behavior (Peattie and Peattie, 2009; McKenzie-Mohr, 2011; White et al., 2019). Notably, from a marketer's innovation perspective, most platform-based services (e.g., car, bike or scooter sharing, delivery services based on predictive modeling) require a minimum density of consumers, which is rarely found in rural areas (Illgen and Höck, 2020). Therefore, to be applicable, marketers must adapt these sustainable, often platform-based concepts to consumers' needs in rural areas. Marketers have recognized that the consumer mind-set fostered by conventional marketing is a key driver of negative environmental impacts (Ripple et al., 2017). Marketing and sustainability are inextricably intertwined because marketing significantly influences consumers to act more sustainably (White et al., 2019). The most prominent concept of sustainable development is the triple bottom line approach (originating in the 
Brundtland Commission): environmental welfare, economic gain and social benefit (Weidner et al., 2020). Therefore, sustainable marketing needs to focus on maintaining or achieving balanced consumption, which is economically, socially and environmentally necessary for sustainable development (Quoquab and Mohammad, 2020).

Notably, sustainable innovations and also the scholarly discussion of their adaption, innovation resistance (Gleim et al., 2013) and the sustainable marketing concepts are frequently tailored for urban markets and consumers. The Nomenclature of Territorial Units for Statistics (NUTS) classification (European Commission. Statistical Office of the European Union, 2020) helps to distinguish between urban and rural living consumers within Europe. Urban consumers are living in large urban areas $\geq 50 \%$ of the population lives in high-density clusters, while rural consumers are living in rural areas $>50 \%$ of the population lives in rural grid cells. Different lifestyles, infrastructure and ways of community building in urban and rural areas inspire divergent contextualization and, consequently, cause people to have different needs that closely link to sustainability (Cugurullo et al., 2020). An early discussion on splintering urbanism (Graham and Marvin, 2001) addressed the needs and opportunities provided by the urban infrastructure for various layers of urban citizens but missed to address the rural consumers. This differentiation is relevant because of the number of people who do not live in large cities. In the EU, only 15 cities (home to $6.5 \%$ of the EU's total population) have more than one million inhabitants. All other people live in smaller cities or rural areas. The structure is comparable in the USA, although there are larger cities, but the UN does not consider this fact in its Sustainable Development Goals (United Nations, 2021), in which the development of urban areas is explicitly emphasized while rural areas are considered only in connection with the poorest of the poor (Zulauf et al., 2017). The example of mobility well illustrates the need to consider urban and rural particularities in affluent societies. While cars are essential to maintaining satisfactory mobility in rural areas, they increasingly hinder mobility in modern urban areas (e.g., due to restricted zones or lack of parking) (Roblek et al., 2021).

The Value-Belief-Norm-Theory is a well-established theory to explain the adoption of sustainability-related innovations (Jansson et al., 2011). Medina et al. (2019) argue that past studies overestimated the individual level of analysis, such as individual norms and beliefs, but underestimated the power of contextual analysis such as group norms, cultural orientations, and economic factors. Therefore, sustainable marketing and innovation research should focus on the contextualization of urban vs. rural consumers for clarifying their particular needs, values, beliefs, and norms which is necessary to explore the consequences for marketers by addressing the following research questions:

- How do conceptualizations of sustainability differ between rural and urban living consumers?

- Which consequences for sustainable marketing and management arise from differences and similarities of upstream innovations with downstream dynamics in urban and rural areas?

This perspective is methodologically based on a conceptual review of previous research on sustainable marketing innovations and illustrative examples from the reality of consumers' lives. The structure of the article is as follows: first, we outline the theoretical background and contextualization; second, we conclude with a discussion.

\section{THEORETICAL BACKGROUND AND CONTEXTUALIZATION}

The application of Value-Belief-Norm Theory (Stern et al., 1993, 1999) to explain sustainable behavior is rooted in Schwartz's norm-activation model of altruism (Schwartz, 1968), which can be used to understand consumers' actions to ameliorate environmental problems. Environmentally friendly behaviors are more likely to occur when people acknowledge their responsibility and are more aware of harmful consequences. Stern et al. (1993) extend Schwartz's model by offering an integrated model of environmental concerns that adds egoistic and biospheric values. In general, values are identified as fundamental orientations and guiding principles serve as the basis for organizing an individual's beliefs and attitudes and for directing individual behavior (Lee et al., 2014). Previous studies show the great relevance of altruistic and egoistic values in shaping sustainable behavior and green purchasing (Birch et al., 2018; Prakash et al., 2019; Zou and Chan, 2019).

A related research stream profiles green consumers based on cultural factors (Strizhakova and Coulter, 2013; Minton et al., 2015) or sociodemographics (Diamantopoulos et al., 2003; Chekima et al., 2016), revealing relatively complex associations of gender, marital status, age, number of children, education, social class, and environmental consciousness. Even when these findings are consolidated with the context and the country, however, sociodemographic variables are of limited use in profiling green consumerism. This supports the call for improved contextualization (Medina et al., 2019) going beyond the individual level.

The disparity in daily routines and in the adoption of sustainable practices between urban and rural areas is obvious. Sustainable mobility is more difficult for people living in rural areas because many platform-based environmental protection technologies are not available or available only to a limited extent and muscle-powered mobility is also not feasible due to rural areas' great distances. This does not mean, however, that the fundamental willingness to act sustainably is less prevalent. Additionally, perceptions of air pollution and reduced biodiversity differ between rural and urban areas. For example, air pollution from exhaust fumes is directly perceptible in larger cities but remains rather abstract in rural areas. By contrast, declining biodiversity (fewer insects, dying trees) is an effect of pollution and climate change that is clearly observed in rural areas. Considering these factors, we assume that both the conceptualization and the motives for sustainable behavior differ 
between urban and rural areas. Notably, these differences have not been considered in theory building but have been reduced to a frame of reference for properly illustrating the empirical results in relevant studies (e.g., Wang et al., 2014; Illgen and Höck, 2020; Yang and Zhang, 2020).

From a marketer's perspective, such findings provide little help in identifying and enacting environmentally sustainable strategies (Gleim et al., 2013). There is a substantial and highly relevant gap in explaining why a vast majority of consumers claim to be pro-environmental yet do not purchase environmentally friendly products (Quoquab and Mohammad, 2020). White et al. (2019) have introduced a framework-Social influence, Habit formation, Individual self, Feelings and cognition and Tangibility (SHIFT)-for rectifying this intention-action gap. Many of their examples of desired behaviors to overcome primary and secondary behavioral barriers (composting, car sharing and reduced driving frequency, riding a bike to work) highlight that the design for acting sustainably must be different in urban and rural areas, as described in the Urban Rural Marketing Environmental Lab (URMEL) framework (see Figure 1).

Marketers and sustainability protagonists need to link upstream innovation with downstream dynamics and vice versa. To do so, they need to match their configuration of offers to meet consumer demand for sustainability. The offers, in turn, must fit the consumers' lifestyles and demands. Acting sustainability is part of a societal discourse in which various interest groups aim to further their agendas (Wilson, 2015), but it remains unclear whether upstream innovations with downstream dynamics are and should be the same in urban and rural areas. Notably, these dynamics arise from the interaction of, on the one hand, consumers' motives to behave sustainably according to their values and, on the other, marketers' innovative offers that respond to those motives. The dynamics considered in Figure $\mathbf{1}$ can follow two basic patterns: Innovations enabling behavioral changes (such as E-scooters) or behavioral changes opening room for innovative products and services (such as package-free grocery retailing). Both types of accelerating dynamics are considered to be enablers to overcome consumers' intention-action gap.

One example is platform-based mobility (ride-sharing, carsharing, scooter rental, etc.) and the motive of environmentally friendly mobility. An accelerating dynamic is evolving through the positive experiences of consumers who are finding a growing number of offers aiming to meet the burgeoning demand of urban consumers. However, these dynamics are enabled by a critical mass; rural consumers cannot take advantage of these innovations in their daily lives. By contrast, rural consumers can improve their emotional state and assuage a guilty conscience about household waste by composting while urban consumers can hardly set up a compost heap in the scarce balcony space available to them.

Based on the Value-Belief-Norm Theory, a more differentiated view addressing the various needs is needed to expand overall sustainability, increase stakeholder acceptance and reduce unnecessary costs for marketers and consumers. Before that, however, the neglected question of whether the understanding of sustainability is the same in rural and urban areas must be comprehensively addressed. To give a placative example, we consider air pollution prevention in urban and rural areas, which is commonly assumed to be motivated by an altruistic value (Stern et al., 1999; Lee et al., 2014). However, in urban areas preventing air pollution might be primary motivated by the aim to protect the owns' and family's health. Therefore, the motivation also could be underpinned by an egoistic value. In contrast, rural living people are less directly affected by pollution, thus the motivation for prevention might be driven by altruistic values. Likewise, the consequences also differ partly for both areas. Urban living people can easily change their behavior by using public transportation or going by bike instead of the car, while this is no option for rural living people. On the other hand, they often have fireplaces for burning leaves, trash, and other materials, but also use wood stoves, which can also be reduced or eliminated.

\section{DISCUSSION}

Answering research question 1 the above research framework prompts scholars to challenge their Value-Belief-Norm Theorybased assumptions. Through the contextualized consideration (Medina et al., 2019) the URMEL framework provides sound reasons to expect that values triggering consumers' motivations for sustainable behavioral changes differs between people living in urban and rural areas as illustrated with the air pollution example. The URMEL framework developed here in contributes to a conceptual progress overcoming the limitations of the conventional marketing practice aiming to profile green consumers (Diamantopoulos et al., 2003). The main contribution of this manuscript is challenging the differences of urban and rural living consumers' perceptions of sustainability at a conceptual, norm-based (Jansson et al., 2011; Gleim et al., 2013), rather than on a technical level (Graham and Marvin, 2001), e.g., critical mass for carsharing.

Research question 2 addresses the consequences. Complementing the modern SHIFT (White et al., 2019), our URMEL framework provides means to overcome consumers' intention-action gap. The innovation adoption mechanisms and dynamics (or lacks thereof) root in the intention-action gap in sustainable consumption. The URMEL framework is compatible with the recently suggested reality checks to increase ecological value in marketing research (van Heerde et al., 2021, p.2). Grasping the first criterion, "Have you looked to the real world of marketing, not just the literature, for ideas?" We clarified the divergences between urban and rural consumers environment, that turned out to be insufficiently covered in marketing scholarly literature (e.g., Chekima et al., 2016). However, we grasp reality check number five, "Do you capture what non-academic experts have written about your topic?" and number nine, "Have you used data patterns to improve theory and reported this discovery process in the paper?" to demonstrate the need to fill the research gap. The URMEL framework captures the relevant real-world qualities by translating both perceptions and limitations of consumers to take advantage of sustainability-related innovations. Addressing reality checks number twelve, "Do you capture important 


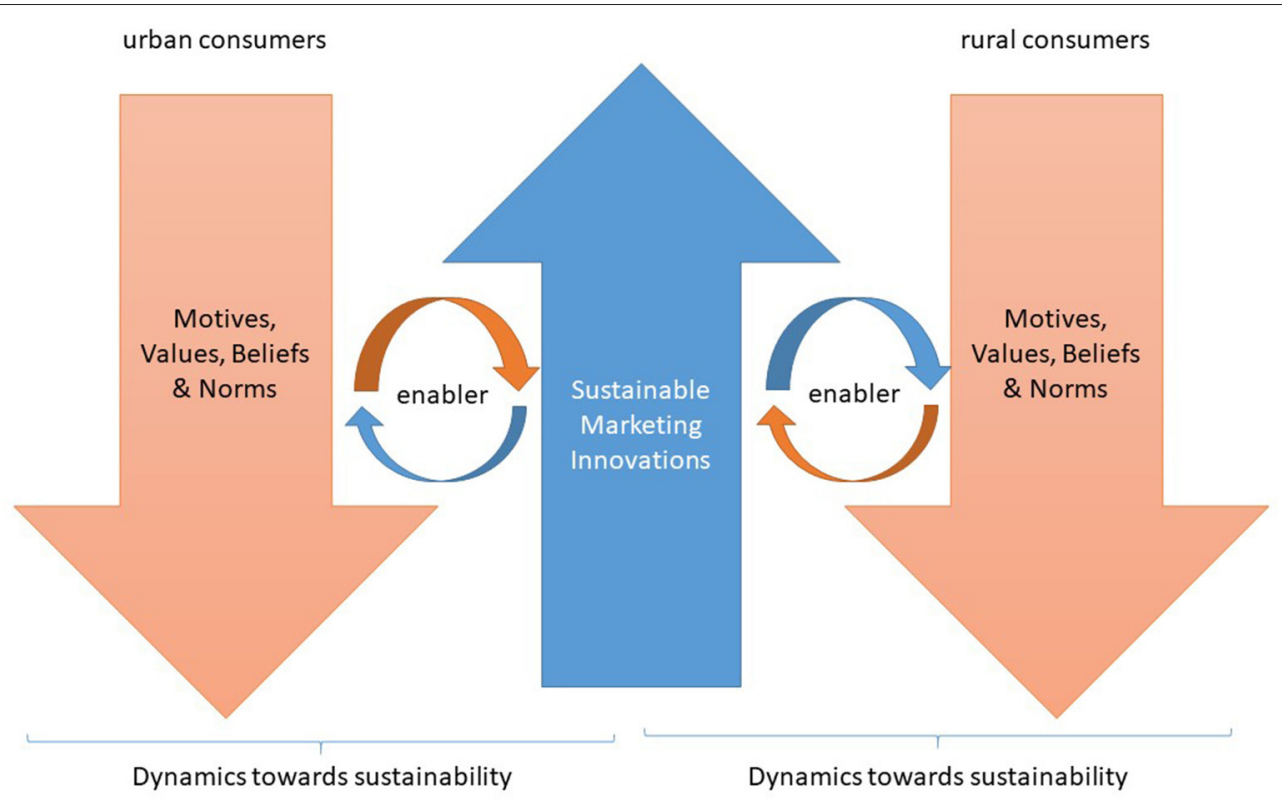

FIGURE 1 | URMEL framework.

real-world qualities encountered and steps enacted by research targets in designing your setting and stimuli?" Reality check thirteen, "Are your dependent variables meaningful to your marketing stakeholder?" and twenty-two, "Have you translated your findings into ideas, metrics, and actions that support stakeholder understanding and decision making" demonstrate the relevance of the URMEL framework of decision-makers, who are well-advised to distinguish between urban and rural consumers' when implementing sustainability interventions and marketing practitioners who might limit the number of potential customers by limiting to the urban scenario only. The URMEL framework offers marketers guidance in developing and implementing sustainability strategies by highlighting and clarifying the consumer needs and market specifics in urban and rural areas. To formulate appropriate strategies, it is necessary to identify drivers and barriers (e.g., Gleim et al., 2013) in sustainable consumption in a way that acknowledges the consumer's conceptualization and everyday life situation. To date, most sustainable innovations have been developed exclusively for urban areas. Considering rural consumers as a target group (e.g., Illgen and Höck, 2020) in their own right, with specific upstream innovations and downstream dynamics as well as their own drivers and barriers, increases the likelihood of successfully implementing strategies to increase sustainability. Consequently, need to address (i) marketers, who will be able to develop and implement concepts adapted to rural areas, (ii) rural consumers, whose sustainable consumption will be facilitated by concepts and offers suitable for them and (iii) policymakers, who need to integrate the particularities of rural people in their policies.

Thus, scholars contribute to exploring whether new research pathways are needed as much current marketing activity is tailored to urban areas (e.g., Cugurullo et al., 2020; Roblek et al., 2021) and often ignores the specific needs of rural living consumers (Illgen and Höck, 2020). Furthermore, a clear theoretical reasoning contributes to addressing the intentionaction gap (White et al., 2019) in sustainable consumption and has the potential to narrow it if the suspected peculiarities and influence prove to be true. Consolidating extant literature, the main contribution of the study arises from consumers divergent conceptualizations of suitable consumption leading to the development of the URMEL framework. Applying the reality checks of van Heerde et al. (2021) provides both a face validation of the framework and guidance for future research.

Such research maximizes the impact on stakeholder thinking (e.g., Weidner et al., 2020) and action by providing conceptual insights and new knowledge about consumers in urban and rural areas that marketers can use to develop appropriate marketing management. The findings will help marketers to identify and enact environmentally sustainable strategies and to elaborate sustainable offers outside their common operating markets (e.g., car sharing in rural areas). For marketers and managers it is important to understand how such offers could be adapted to specific conditions so that they also become profitable. We expect that an increase in sustainability in urban areas can be well-implemented by services while, in rural areas, it must be based more on product innovation. From the policymaker's perspective, this research directly fits clusters 5 and 6 of the future EU agenda (European Comission, 2019). This conceptual study invites scholars in sustainable marketing and innovations for quantitative verification through empirical studies guided by the following questions: (i) Which sustainable motives and values do urban and rural consumers have in common? 
Which makes a difference? (ii) To which extent are enablers of sustainable consumption in urban and rural areas identical? How do they differ? Are there any enablers that work in urban areas but not in rural areas and vice versa? (iii) What are common characteristics of the dynamics (see Figure 1) arising from consumers' motives to behave sustainable according to their values and marketers' innovative sustainable offers, what are differences? And do the dynamics lead to convergence or divergence of the conception of sustainable consumption, the adaption of sustainable innovations, and marketing? Further research needs to clarify the impact of cultural dimensions as operationalized by the Schwartz value system, the Hofstede cultural framework, or the Globe management study on the differences between urban and rural living individuals in their cultural contexts.

Consolidating substantial progress in the change toward sustainable lifestyles calls for a differentiated understanding of sustainability at the conceptual level. Reducing "sustainability" to urban living consumers' conceptualization (e.g., Yang and

\section{REFERENCES}

Birch, D., Memery, J., and Silva Kanakaratne, M., de. (2018). The mindful consumer: balancing egoistic and altruistic motivations to purchase local food. J. Retail. Cons. Serv. 40, 221-228. doi: 10.1016/j.jretconser.2017. 10.013

Chekima, B., Chekima, S., Syed Khalid Wafa, S. A. W., Igau, O. A., and Sondoh, S. L. (2016). Sustainable consumption: the effects of knowledge, cultural values, environmental advertising, and demographics. Int. J. Sustain. Dev. World Ecol. 23, 210-220. doi: 10.1080/13504509.2015.1114043

Cugurullo, F., Acheampong, R. A., Gueriau, M., and Dusparic, I. (2020). The transition to autonomous cars, the redesign of cities and the future of urban sustainability. Urban Geogr. 1-27. doi: 10.1080/02723638.2020.17 46096

Diamantopoulos, A., Schlegelmilch, B. B., Sinkovics, R. R., and Bohlen, G. M. (2003). Can socio-demographics still play a role in profiling green consumers? a review of the evidence and an empirical investigation. J. Bus. Res. 56, 465-480. doi: 10.1016/S0148-2963(01)00241-7

European Comission (2019). Orientations Towards the First Strategic Plan Implementing the Research and Innovation Framework Programme Horizon Europe. Available online at: https://ec.europa.eu/research/pdf/horizon-europe/ ec_rtd_orientations-towards-the-strategic-planning.pdf (accessed February 18, 2021),

European Commission. Statistical Office of the European Union (2020). Eurostat Regional Yearbook: 2020 Edition. Luxembourg: Publications Office.

Gleim, M. R., Smith, J. S., Andrews, D., and Cronin, J. J. (2013). Against the green: a multi-method examination of the barriers to green consumption. J. Retail. 89, 44-61. doi: 10.1016/j.jretai.2012.10.001

Graham, S., and Marvin, S. (2001). Splintering Urbanism: Networked Infrastructures, Technological Mobilities, and the Urban Condition. London: Psychology Press.

Illgen, S., and Höck, M. (2020). Establishing car sharing services in rural areas: a simulation-based fleet operations analysis. Transportation 47, 811-826. doi: 10.1007/s11116-018-9920-5

Jansson, J., Marell, A., and Nordlund, A. (2011). Exploring consumer adoption of a high involvement eco-innovation using value-belief-norm theory. J. Cons. Behav. 10, 51-60. doi: 10.1002/cb.346

Lee, Y., Kim, S., Kim, M.-S., and Choi, J. (2014). Antecedents and interrelationships of three types of pro-environmental behavior. J. Bus. Res. 67, 2097-2105. doi: 10.1016/j.jbusres.2014.04.018

McKenzie-Mohr, D. (2011). Fostering Sustainable Behaviour: An Introduction to Community-Based Social Marketing, 3rd Edn. Philadelphia, PA: New Society.
Zhang, 2020) leaves a significant portion of the population behind, denies and hinders the dynamics of innovation in rural areas of affluent and developed regions of the world, and might even induce innovation resistance. Therefore, this study alerts scientists and practitioners to take into account the conceptual differences and the divergent dynamics of innovation adoption in the development of products and services.

\section{DATA AVAILABILITY STATEMENT}

The original contributions presented in the study are included in the article/supplementary material, further inquiries can be directed to the corresponding author.

\section{AUTHOR CONTRIBUTIONS}

All authors contributed equally to the article and approved the submitted version.

Medina, V., DeRonda, A., Ross, N., Curtin, D., and Jia, F. (2019). Revisiting environmental belief and behavior among ethnic groups in the US. Front. Psychol. 10:629. doi: 10.3389/fpsyg.2019.00629

Minton, E. A., Kahle, L. R., and Kim, C.-H. (2015). Religion and motives for sustainable behaviors: a cross-cultural comparison and contrast. J. Bus. Res. 68, 1937-1944. doi: 10.1016/j.jbusres.2015.01.003

Peattie, K., and Peattie, S. (2009). Social marketing: a pathway to consumption reduction? J. Bus. Res. 62, 260-268. doi: 10.1016/j.jbusres.2008.01.033

Prakash, G., Choudhary, S., Kumar, A., Garza-Reyes, J. A., Khan, S. A. R., and Panda, T. K. (2019). Do altruistic and egoistic values influence consumers' attitudes and purchase intentions towards eco-friendly packaged products? an empirical investigation. J. Retail. Cons. Serv. 50, 163-169. doi: 10.1016/j.jretconser.2019.05.011

Quoquab, F., and Mohammad, J. (2020). A review of sustainable consumption (2000 to 2020): what we know and what we need to know. J. Glob. Mark. 33, 305-334. doi: 10.1080/08911762.2020.1811441

Ripple, W. J., Wolf, C., Newsome, T. M., Galetti, M., Alamgir, M., Crist, E., et al. (2017). World scientists' warning to humanity: a second notice. BioScience 67, 1026-1028. doi: 10.1093/biosci/bix125

Roblek, V., Meško, M., and Podbregar, I. (2021). Impact of car sharing on urban sustainability. Sustainability 13:905. doi: 10.3390/su13020905

Schwartz, S. H. (1968). Words, deeds and the perception of consequences and responsibility in action situations. J. Pers. Soc. Psychol. 10, 232-242. doi: $10.1037 /$ h0026569

Stern, P. C., Dietz, T., Abel, T., Guagnano, G. A., and Kalof, L. (1999). A value-belief-norm theory of support for social movements: the case of environmentalism. Hum. Ecol. Rev. 6, 81-97.

Stern, P. C., Dietz, T., and Kalof, L. (1993). Value orientations, gender, and environmental concern. Environ. Behav. 25, 322-348. doi: 10.1177/0013916593255002

Strizhakova, Y., and Coulter, R. A. (2013). The "green" side of materialism in emerging BRIC and developed markets: the moderating role of global cultural identity. Int. J. Res. Mark. 30, 69-82. doi: 10.1016/j.ijresmar.2012.08.003

United Nations (2021). THE 17 GOALS|Sustainable Development. Available online at: https://sdgs.un.org/goals (accessed February 18, 2021).

van Heerde, H. J., Moorman, C., Moreau, C. P., and Palmatier, R. W. (2021). Reality check: infusing ecological value into academic marketing research. J. Mark. 85, 1-13. doi: 10.1177/00222429219 92383

Wang, P., Liu, Q., and Qi, Y. (2014). Factors influencing sustainable consumption behaviors: a survey of the rural residents in China. J. Cleaner Prod. 63, 152-165. doi: 10.1016/j.jclepro.2013.05.007 
Weidner, K., Nakata, C., and Zhu, Z. (2020). Sustainable innovation and the triple bottom-line: a market-based capabilities and stakeholder perspective. J. Mark. Theory Pract. 29, 141-161. doi: 10.1080/10696679.2020.17 98253

White, K., Habib, R., and Hardisty, D. J. (2019). How to SHIFT consumer behaviors to be more sustainable: a literature review and guiding framework. J. Mark. 83, 22-49. doi: 10.1177/0022242919825649

Wilson, J. P. (2015). The triple bottom line. Int. J. Retail Distrib. Manag. 43, 432-447. doi: 10.1108/IJRDM-11-2013-0210

Yang, X., and Zhang, L. (2020). Diagnose barriers to sustainable development: a study on "desensitization" in urban residents' green purchasing behavior. Sustain. Dev. 28, 143-154. doi: 10.1002/sd.1978

Zou, L. W., and Chan, R. Y. (2019). Why and when do consumers perform green behaviors? an examination of regulatory focus and ethical ideology. J. Bus. Res. 94, 113-127. doi: 10.1016/j.jbusres.2018.04.006
Zulauf, K., Raab, K., and Wagner, R. (eds.). (2017). "Marketing concepts and their relevance at the Bop: consolidating research on entrepreneurship to alleviate poverty," in EMAC (European Marketing Academy) Conference 2017 (Groningen).

Conflict of Interest: The authors declare that the research was conducted in the absence of any commercial or financial relationships that could be construed as a potential conflict of interest.

Copyright (c) 2021 Zulauf and Wagner. This is an open-access article distributed under the terms of the Creative Commons Attribution License (CC BY). The use, distribution or reproduction in other forums is permitted, provided the original author(s) and the copyright owner(s) are credited and that the original publication in this journal is cited, in accordance with accepted academic practice. No use, distribution or reproduction is permitted which does not comply with these terms. 